practitioners, and with hospitals directly (across "Chinese walls" if in their own district health authority).

Do other general practitioners feel like this? If so we should, as a group, throw a spanner in the works in the long term interest of patients. The financial incentives laid out boldly for us in Funding General Practice ${ }^{1}$ will be better spent on capturing the NHS share of a considerably smaller labour market in 1995. If there are no genera practitioners with budgets Working for Patients will still proceed but a large plank of the market philosophy will be removed and perhaps the whole project will stay afloat for a shorter period.

IAN COCKS

Gloucestershire GL18 1JD

Department of Health. Funding general practice. London: $\mathrm{OH}, 1989$

\section{Blood transfusion in Europe}

SIR,-Dr John D Cash need not look as far as Brussels for challenges to our blood supply. Government proposals for England and Wales will require that the provision of blood services must be "cost-effective . . . and consistent with the wider management changes that are being introduced in the National Health Service." Thus blood and blood products will acquire a cash value and will be available to the prescribing clinician only if there are funds to pay for them. This must be a cause of concern to the transfusion service itself and to both the clinician and the blood donor (who until now have enjoyed medical and scientific, rather than commercial, relationships with the blood transfusion centre)

Elsewhere in Europe there are independent associations of unpaid blood donors which discuss their concerns with the transfusion services. These consultations have ensured the continued integrity of ethical blood services and have enhanced donor motivation. Without such an independent organisation of blood donors in England and Wales transfusion centres will be unable to establish accurately the proportion of the one million donors who share my concerns but who may have no way of expressing them other than with their feet. Only by donor consultation and consent can transfusion centres predict whether the NHS reorganisation will leave them with enough donors to provide European, national, or even regional self sufficiency in blood and blood products.

PETER FELDMAN

Oxford OX+3PA

1 Cash JD. Blood transfusion services and the European Community. Br.Med f 1990;300:481-2. (24 February.

\section{Drug Points}

\section{Arterial thrombosis after treatment with bleomycin and cisplatin}

Drs I W H Garstin, G G CoOper, and J M HooD (Vascular Surgery Unit, Royal Victoria Hospital, Belfast BT 12 6BA) write: Antineoplastic drug therapy has been associated with the development of several cardiovascular diseases.' Some of these drugs are probably toxic to vascular endothelium ${ }^{2}$ and increase the tendency to thrombosis which is a feature of malignant disease. We describe a patient who developed thrombosis of the popliteal, tibial, and peroneal arteries after treatment with cisplatin, etoposide, and bleomycin.

A 35 year old man presented with a two week history of coldness and pallor of his right foot. He had never been a tobacco smoker and was not diabetic but did have raised fasting serum cholesterol and triglyceride concentrations. In 1979 he had undergone right orchidectomy and radiotherapy for a malignant teratoma of the right testis. In November 1988 left orchidectomy was performed for a similar lesion. Computed tomography showed mediastinal lymphadenopathy and parenchymal deposits in the right lung. In December 1988 he started taking combination chemotherapy in 21 day cycles: cisplatin $40 \mathrm{mg}$ intravenously days $1-5$, etoposide $200 \mathrm{mg}$ intravenously days 1-3, and bleomycin $30 \mathrm{mg}$ intravenously days 2,9 , and 16 . Six days after starting the second cycle of treatment he suddenly developed coldness and pallor of his right foot. Transfemoral arteriography showed right popliteal artery occlusion. Thrombus was retrieved from the popliteal artery using an embolectomy catheter with a satisfactory clinical result. One day after the start of the fourth cycle of chemotherapy he again developed an acutely ischaemic right leg. Three surgical attempts to restore patency to the popliteal and distal arteries were followed by further thrombosis despite systemic anticoagulation. At operation perivascular oedema was noted in the region of the popliteal trifurcation and the vessel walls were unusually thick. Operative arteriography of the disobliterated posterior tibial artery showed a narrow and irregular luminal surface. The limb remained viable, although the patient had calf claudication after walking for a few yards. On the assumption that the underlying process was an arteritis he was given oral prednisolone. He continued to receive chemotherapy, and a computed tomogram in April showed no evidence of intrathoracic metastases.

Raynaud's phenomenon occurs in up to $41 \%$ of patients after treatment with the combination of bleomycin and cisplatin. ${ }^{3}$ Arteriographically, diffuse narrowing of digital arteries consistent with a vasculitis process has been found. Several cases of fatal coronary artery disease have been reported in young men similarly treated. ${ }^{+6}$ Our patient's symptoms had a clear temporal relation to his treatment with cisplatin, etoposide, and bleomycin. Macroscopically and arteriographically his popliteal and tibial arteries were diffusely diseased. We suggest that the use of these drugs in combination may carry a risk of serious peripheral vascular complications.

1 Doll DC, Ringenberg OS, Yarbro JW. Vascular toxicity associated with antineoplic ane 7 Clin Oncol 1986;4:1405-17. Nicolson GL. Custead SE Effects of Chen Oncol 1986;4.1405-17. platelet and metastatic tumour cell-endothelial interactions as model for assessing vascular endothelial integrity. Cancer Res 1985; 45:331-6

3 Vogelzang NJ, Bosl GJ, Johnson K, Kennedy BJ. Raynaud's phenomenon: a common toxicity after combination chemotherapy for testicular cancer. Ann Intern Med 1981;95:288-92.

4 Bodensteiner DC. Fatal coronary artery fibrosis after treatmen with bleomycin, vinblastine and cis-platinum. South Med $\mathcal{J}$ 1981;74:898-9.

5 Vogelzang NJ, Torkelson JL, Kennedy BJ. Hypomagnesemia, renal dysfunction and Raynaud's phenomenon in patient renal dysfunction and Raynauds phenomenon in patients treated with cis

6 Doll DC, List AF, Greco FA, et al. Acute vascular ischemic Doll DC, List AF, Greco FA, et al. Acute vascular ischemic
events after cisplatin-based combination chemotherapy for germ-cell tumours of the testis. Ann Intern Med 1986;105 48-51.

\section{Oesophageal lesions during treatment with piroxicam}

Drs L Santucci, L Patoia, S Fiorucci, F Farroni, Del Favero, and A Morelli (Department of Internal Medicine, Policlinico Monteluce, 06100 Perugia, Italy) write: Gastrointestinal lesions often occur in patients taking non-steroidal anti-inflammatory drugs, but damage to the oesophageal mucosa is rare $^{12}$ and is generally attributed to prolonged contact between the drug and the oesophageal mucosa, probably through incorrect administration - for example, swallowing without enough water-and anatomical or functional predisposing factors (stenosis, motor dysfunction).

We report the incidence of oesophageal lesions in 79 young healthy volunteers enrolled in three double blind randomised studies designed to compare the gastrointestinal toxicity of standard piroxicam and piroxicam- $\beta$-cyclodestrine capsules $(20 \mathrm{mg} /$ day) with that of placebo. All the subjects had normal findings on pretreatment endoscopy, but nine of the 57 volunteers treated with nonsteroidal anti-inflammatory drugs were found to have grade I-III lesions ${ }^{+}$after treatment: slight to moderate oesophagitis (5), ulcerative oesophagitis (2), and membranous oesophagitis (2). The two cases of ulcerative oesophagitis and the two of membranous lesions are reported below.

Case $1-\mathrm{A} 20$ year old male smoker was randomised to receive $20 \mathrm{mg} / \mathrm{day}$ piroxicam. No symptoms were recorded during the study. Endoscopy at the end of the study showed a $0 \cdot 3 \mathrm{~cm}$ diameter ulcer in the lower third of the oesophagus. This healed after four weeks' treatment with ranitidine and sucralfate.

Case 2-A 27 year old woman, a non-smoker, was randomised to receive $20 \mathrm{mg} /$ day piroxicam. After six days' treatment she complained of heartburn and vomiting after taking the drug. Endoscopy performed the same day showed membranous oesophageal lesions from the middle to the lower third. Histological and histomicrobiological examinations and culture of membranes showed only necrotic debris. Treatment was stopped and symptoms completely disappeared within six days without treatment. Endoscopy performed 13 days later showed normal findings.

Case 3-A 20 year old man, a non-smoker, was randomised to receive $20 \mathrm{mg} /$ day piroxicam. He suffered heartburn throughout the treatment period but did not discontinue the drug. At the end of the study endoscopy showed whitish, only partially removable, pseudomembranes in the lower oesophagus. Histological examination showed necrotic material. Cultures were negative. No treatment was given, and control endoscopy performed four weeks later showed normal oesophageal mucosa.

Case 4-A 21 year old man, a non-smoker was randomised to receive $20 \mathrm{mg} /$ day piroxicam- $\beta$ cyclodestrine. He suffered slight intermitten heartburn, and endoscopy at the end of the study showed four serpiginous $0.4 \mathrm{~cm}$ ulcers in the lower oesophagus. Complete healing was shown after six weeks' treatment with ranitidine and sucralfate.

As far as we know, only one case of oesophagea ulcer due to piroxicam has been reported, and this was in a patient with proved pathologica gastro-oesophageal reflux. ${ }^{3}$ Our data show that oesophageal lesions are far from rare during piroxicam treatment.

\section{Heller SR, Fellows IW, et al. Non-steroidal anti-inflammator drugs and benign oesophageal stricture. $\mathrm{Br} \mathrm{Med}$ f 1982;285: $167-8$ \\ 2 Kikendall JW, Friedman AC, Oyewole MA, Fleischer D, Johnson LF. Pill-induced esophageal injury" case reports and review of the medical literature. Dig Dis $S c i 1983: 28: 174-82$ \\ 3 Coates AG, Nostrant TT, Wilson JA, Elta $\mathrm{CH}$ Agha $\mathrm{FP}$. Esophagitis caused by non-steroidal-antiinflammary Esophagitis caused by non-steroidal-antinflammatory medication: case repors and review of the lictature on

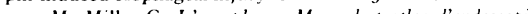 d'endoscopie. Soleure: Gassmann, 1977.}

\section{Correction}

\section{Electrical arcing and contact lenses}

A printers' error and an editorial error occurred in this letter by $\mathrm{Mr} \mathrm{R}$ J Buckley ( 24 March, p 816). The temperature rise described in the second paragraph was of $8-10^{\circ} \mathrm{C}$ and not $810^{\circ} \mathrm{C}$ as published, and the las sentence should refer to ultraviolet-absorbing contact lenses and not ultraviolet contact lenses as published. 